\title{
ANALISA KEMAMPUAN TENAGA KERJA KONSTRUKSI DENGAN DAN TANPA MEMILIKI SERTIFIKAT KEAHLIAN KERJA (SKA) DI KOTA SEMARANG
}

\author{
Anandhita Rizky $\mathbf{P}^{1}$ Mochammad Ivall $\mathbf{R}^{2}$ Hari Setijo Pudihadjo ${ }^{3}$ Bambang Tutuko ${ }^{4}$ \\ Jurusan Teknik Sipil Fakultas Teknik Universitas Semarang Jalan Arteri Sukarno Hatta - \\ Semarang
}

\begin{abstract}
There are still many construction workers who do not have it. This study aims to determine the ability of construction workers who have and without having a Work Expertise Certificate in the city of Semarang. The sample studied was construction workers in the city of Semarang. The methods used in data collection are two types, primary data and secondary data. Primary data is obtained by using a structured questionnaire consisting of 35 questions that are asked, which are related to the ability of the construction workforce that has and without having a Work Expertise Certificate in the city of Semarang. Questions in the questionnaire were made using a Likert scale of the questions given to respondents, namely from numbers 1 to 4 where number 1 shows the statements in the questionnaire are not applied to the project undertaken by the respondent and number 4 or the higher the value the statement in the questionnaire is higher the level of application of the use of the Certificate of Work Skill for construction workers in the city of Semarang. From the results of the study showed that the workforce with a certificate applies more of its ability in the construction field compared to workers who do not have a Job Skill Certificate.
\end{abstract}

Keywords: Certificate of Work Skill; Construction; Workforce

\begin{abstract}
ABSTRAK
Masih banyak dijumpai tenaga kerja konstruksi yang belum memiliki Sertifikat Keahlian, seperti yang disyaratkan dalam Undang - Undang Jasa Konstruksi. Penelitian ini bertujuan untuk mengetahui kemampuan tenaga kerja konstruksi yang memiliki dan tanpa memiliki Sertifikat Keahlian Kerja di kota Semarang. Sampel yang diteliti adalah tenaga kerja konstruksi di kota Semarang. Metode yang digunakan dalam pengumpulan data ada 2 yaitu data primer dan data sekunder. Dari data primer digunakan penyebaran kuesioner yang terstruktur terdiri dari 35 pertanyaan yang diajukan, yang berkaitan dengan kemampuan tenaga kerja konstuksi yang memiliki dan tanpa memiliki Sertifikat Keahlian Kerja di kota Semarang. Pertanyaan dalam kuesioner dibuat dengan menggunakan skala likert dari pertanyaan yang diberikan kepada responden, yaitu dari angka 1 hingga 4 dimana angka 1 menunjukan pernyataan di dalam kuesioner tidak diterapkan bagi proyek yang dikerjakan oleh responden dan angka 4 atau semakin tinggi nilainya pernyataan di dalam kuesioner semakin tinggi tingkat penerapan penggunaan Sertifikat Keahlian Kerja bagi tenaga kerja konstruksi di kota Semarang. Dari hasil penelitian menunjukan tenaga kerja yang bersertikat lebih banyak menerapkan kemampuannya dalam bidang konstruksi dibandingkan dengan tenaga kerja yang tidak memiliki Sertifikat Keahlian Kerja.
\end{abstract}

Kata kunci : Sertifikat Keahlian Kerja, Tenaga Kerja; Konstruksi 


\section{PENDAHULUAN}

Tenaga Kerja Konstruksi adalah orang yang berhubungan dengan hasil kegiatan proyek konstruksi. Mutu produksi tergantung dari mutu tenaga kerja yang terlibat. Kesiapan tenaga kerja berkualitas dapat menunjang proses pekerjaan konstruksi yang aman, bermutu serta suistable. Untuk membuat tenaga kerja konstruksi di Indonesia menjadi kokoh, handal, berdaya saing tinggi dan menghasilkan pekerjaan konstruksi yang berkualitas, setiap tenaga kerja konstruksi harus memiliki Sertifikat Keahlian (SKA).

Data dari Kementerian Pekerjaan Umum Tahun 2011 menyatakan dari 5,3 juta tenaga konstruksi di Indonesia, baru sekitar 348.077 pekerja atau 7 persen yang telah memiliki sertifikat. Ketua Lembaga Pengembangan Jasa Konstruksi (LPJK) Provinsi Jateng Ir. M. Satya Joewana mengungkapkan di Jateng jumlah tenaga kerja jasa konstruksi yang memiliki SKT 22.490 orang dan SKA 8.597 orang, disamping itu badan usaha yang memiliki Sertifikat Badan Usaha (SBU) sebanyak 13.190. Kebutuhan tenaga kerja di bidang jasa konstruksi, baik tingkat terampil maupun ahli yang bersertifikat keterampilan dan keahlian di Jateng masih sangat langka. Padahal, sesuai dengan UU No.18 Tahun 1999 tentang Jasa Konstruksi, semua tenaga kerja jasa konstruksi harus memiliki Sertifikat Keterampilan (SKT) dan Sertifikat Keahlian (SKA). Kekurangan tenaga ahli konstruksi yang bersertifikat hendaknya menjadi perhatian, khususnya masyarakat jasa konstruksi sebab masalah tersebut menunjukkan rendahnya daya saing industri konstruksi nasional. Indonesia belum mampu bersaing dengan negara tetangga seperti Singapura, Brunei, Malaysia, Thailand dan Filipina.

SKA adalah tools untuk mempresentasikan bahwa tenaga ahli tersebut memiliki kompetensi sesuai kualifikasi dan klasifikasi yang tercantum pada sertifikat keahliannya. Sertifkat Keahlian Kerja dapat memberikan beberapa manfaat bagi masyarakat jasa konstruksi. Beberapa manfaat yang akan diperoleh tenaga ahli konstruksi adalah mendapatkan pendapatan yang lebih tinggi, juga mendapat pengakuan yang resmi terhadap kompetensi dan profesionalisme yang dimilikinya dan tersedianya kesempatan peningkatan kompetensi dan profesionalisme itu melalui pembinaan keprofesian yang berkelanjutan dan terbukanya akses langsung ke pasaran tenaga kerja keinsinyuran di luar negeri. Berdasarkan latar belakang dan rumusan masalah tersebut maka tujuan penelitian ini untuk mengetahui kemampuan tenaga kerja kontruksi dengan dan tanpa memiliki Sertifikat Keahlian Kerja (SKA) di kota Semarang. 


\section{METODOLOGI PENELITIAN}

Metodologi dari penelitian ini tertera dalam Gambar 1.

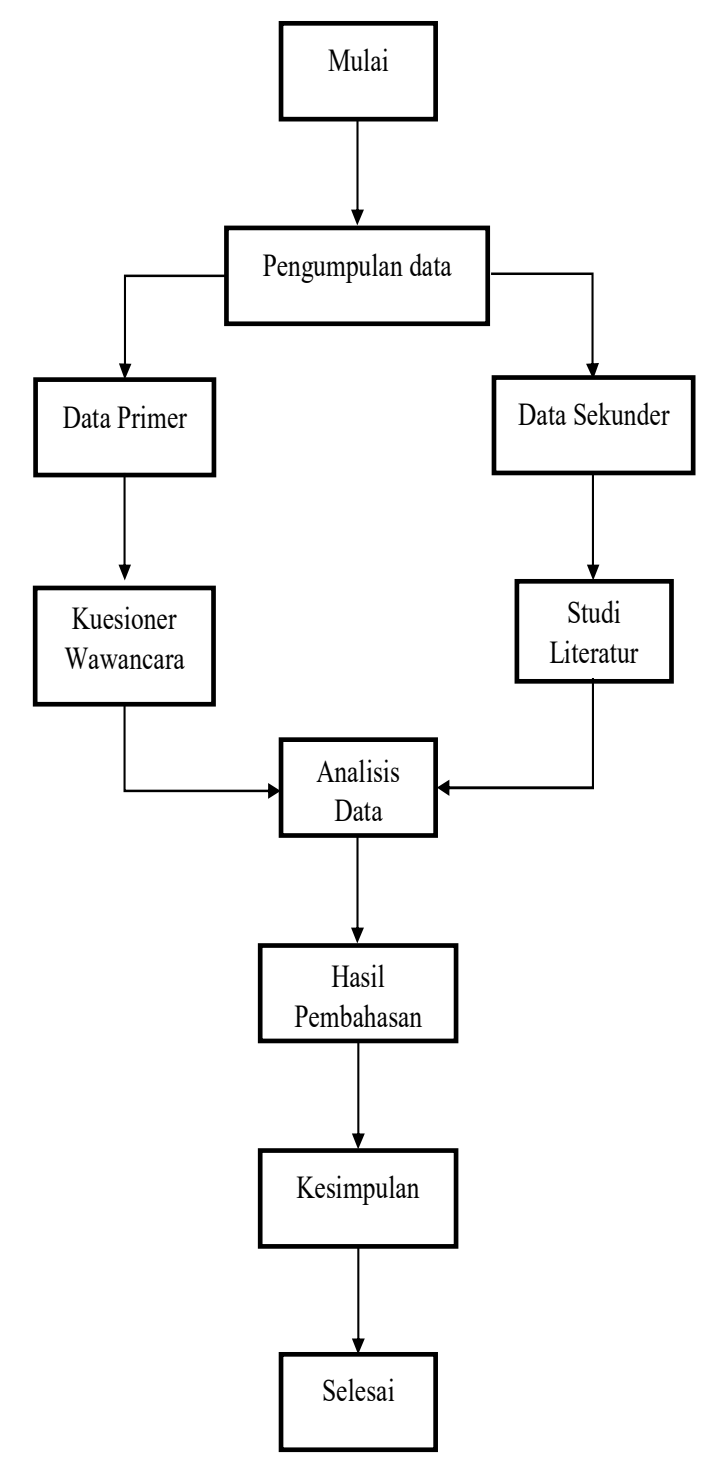

Gambar 1. Metodologi Penelitian

Sumber : Peneliti, 2018

\section{HASIL DAN PEMBAHASAN}

Penelitian ini dalam analasisnya menggunakan bantuan komputer yaitu program Microsoft Excel, yang secara garis besar menjadi 2 ( dua ) bagian yaitu analitis data deskriptif untuk responden statistik deskriptif. Variabel tentang kemampuan tenaga kerja konstruksi dengan dan tanpa memiliki Sertifikat Keahlian Kerja (SKA) di kota Semarang dengan range 1 - 4 . Untuk penilaian tentang penerapan sebagai berikut:

1 : Tidak Diterapkan ( TD )

2 : Kurang Diterapkan ( KD )

3 : Diterapkan ( D )

4 : Sangat Diterapkan ( SD )

Rumus untuk analisis data adalah sebagai beriku : 


$$
\sum_{x=\frac{i=1}{n}}^{i=n} x i
$$

Keterangan :

$x$ : rerata nilai faktor

$\mathrm{Xi}$ : nilai faktor pada responden $\mathrm{ke}-\mathrm{i}$

$\mathrm{N}$ : volume responden

Selanjutnya untuk menentukan urutan rangking dari hasil kuisioner dengan menghitung nilai indeks kepentingan relative (IKR). Digunakan rumus :

Keterangan:

$$
\mathrm{IKR}=\frac{\mathrm{X}}{\mathrm{M}}
$$

IKR : Indeks Kepentingan Relatif

$\mathrm{M}$ : Jangkauan nilai faktor

$\mathrm{N}: 4$

Variabel yang mempunyai IKR paling tinggi diberikan rangking 1 , seterusnya sampai IKR paling rendah secara berurutan. Bila dijumpai 2 atau lebih dari nilai IKR sama, maka untuk mementukan rangking adalah melalui penjumlahan rangking yang mewakili, selanjutnya dikomparasi dengan banyaknya variabel yang bernilai sama. Metode analisis ini akan sangat berguna untuk mengindetifikasi rangking responden dan member prioritas terhadap variabel studi. Hasil dari analisis ditunjukkan pada Tabel 1 dan 2.

Tabel 1. Dengan susunan urutan rangking berdasarkan skor kemampuan Tenaga Kerja Kontruksi yang Memiliki Sertifikat Keahlian Kerja (SKA) di Kota Semarang

\section{No. Bagaimana Kemampuan Tenaga Kerja Mea Rangkin Keterangan Kontruksi yang Memiliki Sertifikat Keahlian Kerja (SKA) di Kota Semarang}

1 Memiliki kemampuan berkomunikasi yang baik

4.00

1

Sangat Diterapkan

2 Mampu memahami gambar atau desain rencana pada proyek

Sangat Diterapkan

3 Profesionalisme dalam bekerja di proyek

Sangat Diterapkan

4 Memiliki inovasi tersendiri dalam menyelesaikan pekerjaan

Sangat Diterapkan

5 Keinginan untuk menghasilkan hasil pekerjaan yang bagus

Sangat Diterapkan

6 Menerapakan metode kerja yang dikuasai pada bidangnya

Sangat Diterapkan

7 Menerapkan penggunaan alat dan bahan pada bidangnya

Sangat Diterapkan

8 Melaksanakan pekerjaan dengan percaya diri 
9 Menerapkan standar keselamatan pada

10 Melaksanakan prosedur standar keselamatan saat bekerja pada bidangnya

$3.61 \quad 10 \quad$ Sangat Diterapkan

11 Memiliki kompetensi lebih dari tenaga kerja lain yang sebidang

3.61 $11 \quad$ Sangat Diterapkan

12 Mampu memimpin sebuah tim kerja dalam proyek

$3.57 \quad 12 \quad$ Sangat Diterapkan

13 Bekerja sesuai waktu yang yang sudah dijadwalkan oleh proyek

$3.43 \quad 13 \quad$ Sangat Diterapkan

14 Bekerja dengan mengikuti arahan dari atasan

Sangat Diterapkan

15 Keinginan untuk bekerja keras bagi proyek

Sangat Diterapkan

16 Sedikit melakukan pekerjaan ulang/rework

Sangat Diterapkan

17 Sedikit menghasilkan waste material

Sangat Diterapkan

18 Mampu dalam menghadapi permintaan industri konstruksi

Sangat Diterapkan

19 Bekerja dengan menggunakan alat dan bahan secara efektif

Sangat Diterapkan

20 Bekerja sesuai dengan rencana yang telah disepakati

Sangat Diterapkan

21 Mengetahui hukum dan peraturan yang ada dalam dunia konstruksi

Sangat Diterapkan

22 Memiliki kemampuan manajemen proyek yang baik

Sangat Diterapkan

23 Bekerja mengikuti standar aturan dalam proyek

Sangat Diterapkan

24 Memiliki keinginan untuk terus belajar mengenai pekerjaan konstruksi

Sangat Diterapkan

25 Bekerja dengan metode kerja yang benar

Sangat Diterapkan

26 Bekerjasama dengan anggota tenaga kerja lain 
27 Mendapat gaji yang lebih tinggi dari tenaga kerja

28 Mampu menganalisa suatu kesalahan pekerjaan

Diterapkan dalam proyek

29 Mampu beradaptasi dengan kondisi proyek yang berbeda-beda

Diterapkan

32 Memiliki kemampuan di bidang tertentu dalam dunia konstruksi

33 Mampu bersaing dengan tenaga kerja lainnya

Diterapkan yang sebidang

34 Mampu menggunakan teknologi-teknologi yang sudah diperbaharui

Kurang Diterapkan

35 Memiliki pengetahuan dalam bidang IT yang berguna bagi proyek

Pada Tabel 1 tersebut menunjukkan bahwa kemampuan Tenaga Kerja Kontruksi yang memiliki Sertifikat Keahlian Kerja (SKA) di Kota Semarang, menempati rangking pertama dengan skor kemampuan 4.00, peringkat kedua dengan skor kemampuan 3.87 tenaga kerja yang memliki kemampuan memahami gambar atau desain rencana pada proyek kosntruksi, peringkat ketiga dengan skor 3.87 dengan tenaga kerja memiliki kemampuan profesionalisme dalam bekerja di proyek yang artinya mampu berkomitmen pada apa yang dia kerjakan di proyek konstruksi.

Tabel 2. Dengan susunan urutan rangking berdasarkan skor kemampuan Tenaga Kerja Kontruksi yang Tidak Memiliki Sertifikat Keahlian Kerja (SKA) di Kota Semarang

\section{No. Bagaimana Kemampuan Tenaga Kerja Mean Rangking Keterangan Kontruksi yang Tidak Memiliki Sertifikat Keahlian Kerja (SKA) di Kota Semarang}

$1 \quad$ Memiliki kemampuan berkomunikasi yang baik $\quad 3.45 \quad 1 \quad$ Sangat Diterapkan

\begin{tabular}{lllll}
2 & $\begin{array}{l}\text { Menerapkan penggunaan alat dan bahan pada } \\
\text { bidangnya }\end{array}$ & 3.00 & 2 & Diterapkan \\
\hline 3 & $\begin{array}{l}\text { Menerapkan standar keselamatan pada } \\
\text { bidangnya }\end{array}$ & 3.00 & 3 & Diterapkan
\end{tabular}




\begin{tabular}{clccc}
\hline $\mathbf{4}$ & Bekerja dengan metode kerja yang benar & 3.00 & 4 & Diterapkan \\
\hline $\mathbf{5}$ & $\begin{array}{l}\text { Bekerja sesuai dengan rencana yang telah } \\
\text { disepakati }\end{array}$ & 3.00 & 5 & Diterapkan \\
\hline $\mathbf{6}$ & $\begin{array}{l}\text { Mampu memahami gambar atau desain rencana } \\
\text { pada proyek }\end{array}$ & 3.00 & 6 & Diterapkan \\
\hline
\end{tabular}




\begin{tabular}{|c|c|c|c|c|}
\hline 7 & Bekerjasama dengan anggota tenaga kerja lain & 3.00 & 7 & Diterapkan \\
\hline 8 & $\begin{array}{l}\text { Mampu memimpin sebuah tim kerja dalam } \\
\text { proyek }\end{array}$ & 3.00 & 8 & Diterapkan \\
\hline 9 & Bekerja mengikuti standar aturan dalam proyek & 3.00 & 9 & Diterapkan \\
\hline 10 & $\begin{array}{l}\text { Keinginan untuk menghasilkan hasil pekerjaan } \\
\text { yang bagus }\end{array}$ & 3.00 & 10 & Diterapkan \\
\hline 11 & Profesionalisme dalam bekerja di proyek & 3.00 & 11 & Diterapkan \\
\hline 12 & Mampu bekerja di bawah tekanan & 3.00 & 12 & Diterapkan \\
\hline 13 & $\begin{array}{l}\text { Memiliki keinginan untuk terus belajar mengenai } \\
\text { pekerjaan konstruksi }\end{array}$ & 3.00 & 13 & Diterapkan \\
\hline 14 & $\begin{array}{l}\text { Menerapakan metode kerja yang dikuasai pada } \\
\text { bidangnya }\end{array}$ & 2.82 & 14 & Diterapkan \\
\hline 15 & $\begin{array}{l}\text { Bekerja dengan menggunakan alat dan bahan } \\
\text { secara efektif }\end{array}$ & 2.82 & 15 & Diterapkan \\
\hline 16 & $\begin{array}{l}\text { Bekerja sesuai waktu yang yang sudah } \\
\text { dijadwalkan oleh proyek }\end{array}$ & 2.82 & 16 & Diterapkan \\
\hline 17 & Bekerja dengan mengikuti arahan dari atasan & 2.82 & 17 & Diterapkan \\
\hline 18 & Melaksanakan pekerjaan dengan percaya diri & 2.82 & 18 & Diterapkan \\
\hline 19 & Keinginan untuk bekerja keras bagi proyek & 2.82 & 19 & Diterapkan \\
\hline 20 & $\begin{array}{l}\text { Melaksanakan prosedur standar keselamatan } \\
\text { saat bekerja pada bidangnya }\end{array}$ & 2.68 & 20 & Diterapkan \\
\hline 21 & $\begin{array}{l}\text { Memiliki kemampuan di bidang tertentu dalam } \\
\text { dunia konstruksi }\end{array}$ & 2.68 & 21 & Diterapkan \\
\hline 22 & $\begin{array}{l}\text { Mampu dalam menghadapi permintaan industri } \\
\text { konstruksi }\end{array}$ & 2.45 & 22 & Kurang Diterapkan \\
\hline 23 & $\begin{array}{l}\text { Memiliki kemampuan manajemen proyek yang } \\
\text { baik }\end{array}$ & 2.45 & 23 & Kurang Diterapkan \\
\hline 24 & & 2.45 & 24 & Kurang Diterapkan \\
\hline
\end{tabular}




\begin{tabular}{|c|c|c|c|c|}
\hline & $\begin{array}{l}\text { Mampu beradaptasi dengan kondisi proyek yang } \\
\text { berbeda-beda }\end{array}$ & & & \\
\hline 25 & Tidak terlambat menyelesaikan pekerjaan & 2.45 & 25 & Kurang Diterapkan \\
\hline 26 & $\begin{array}{l}\text { Mampu bersaing dengan tenaga kerja lainnya } \\
\text { yang sebidang }\end{array}$ & 2.45 & 26 & Kurang Diterapkan \\
\hline 27 & $\begin{array}{l}\text { Memiliki kompetensi lebih dari tenaga kerja lain } \\
\text { yang sebidang }\end{array}$ & 2.45 & 27 & Kurang Diterapkan \\
\hline 28 & $\begin{array}{l}\text { Memiliki inovasi tersendiri dalam menyelesaikan } \\
\text { pekerjaan }\end{array}$ & 2.45 & 28 & Kurang Diterapkan \\
\hline 29 & $\begin{array}{l}\text { Mampu menganalisa suatu kesalahan pekerjaan } \\
\text { dalam proyek }\end{array}$ & 2.27 & 29 & Kurang Diterapkan \\
\hline 30 & $\begin{array}{l}\text { Mengetahui hukum dan peraturan yang ada } \\
\text { dalam dunia konstruksi }\end{array}$ & 2.27 & 30 & Kurang Diterapkan \\
\hline 31 & Sedikit melakukan pekerjaan ulang/rework & 2.27 & 31 & Kurang Diterapkan \\
\hline 32 & Sedikit menghasilkan waste material & 2.14 & 32 & Kurang Diterapkan \\
\hline 33 & $\begin{array}{l}\text { Mendapat gaji yang lebih tinggi dari tenaga kerja } \\
\text { lainnya yang tidak memiliki SKA }\end{array}$ & 1.32 & 33 & Tidak Diterapkan \\
\hline 34 & $\begin{array}{l}\text { Mampu menggunakan teknologi-teknologi yang } \\
\text { sudah diperbaharui }\end{array}$ & 1.14 & 34 & Tidak Diterapkan \\
\hline 35 & $\begin{array}{l}\text { Memiliki pengetahuan dalam bidang IT yang } \\
\text { berguna bagi proyek }\end{array}$ & 1.00 & 35 & Tidak Diterapkan \\
\hline
\end{tabular}

Sumber : Peneliti, 2018 
Pada Tabel 2 tersebut, kemampuan tenaga kerja Kontruksi yang Tidak Memiliki Sertifikat Keahlian Kerja (SKA) di Kota Semarang yang menempati rangking pertama dengan skor kemampuan 3.45, peringkat ke dua degan skor kemampuan 3.00, peringkat ke tiga dengan skor kemampuan 3.00. Tenaga kerja konstruksi yang tidak memiliki Sertifikat Keahlian Kerja di Kota Semarang tidak menerapkan kemampuan penggunakan teknologi-teknologi yang sudah diperbaharui, tidak memiliki pengetahuan dalam bidang IT yang berguna bagi proyek dan tidak mendapat gaji yang lebih tinggi dari tenaga kerja lainnya yang memiliki SKA.

\section{KESIMPULAN}

Tenaga Kerja Konstruksi yang memiliki dan yang tidak memiliki Sertifikat Keahlian Kerja di kota Semarang sebagian besar menerapkan kemampuan berkomunikasi secara baik serta dapat bersosialisai dengan baik, dan memiliki kekurangan dalam bidang IT serta perkembangan teknologi yang lebih modern untuk kemajuan proyek konstruksi di Indonesia.

\section{DAFTAR PUSTAKA}

Adi, H. P., dan Adillah, S. U. 2012. Sertifikat Tenaga Kerja Konstruksi Sebagai Unsur Pendukung Pembangunan Infrastrukstur.

Haryadi, B. 2010. Kompetensi Tenaga Kerja Konstruksi dalam Menghadapi Era Liberalisasi, Yogyakarta, Universitas Negeri Yogyakarta.

Jelantik, I.M. 2014. Analisis Faktor yang Mempengaruhi Tenaga Kerja Konstruksi untuk Memiliki SKA/SKTK pada Kontraktor di Kabupaten Badung, Bandung : Universitas Udayana.

Kesai, P., dan Arifin, D. Z. 2012. Kinerja SDM Kontruksi, Jakarta.

Peraturan Pemerintah Republik Indonesia Nomor 28 Tahun 2000 Tentang Usaha dan Peran Jasa Kontruksi.

Peraturan Pemerintah Republik Indonesia Nomor 59 Tahun 2010 Tentang Penyelenggaran Jasa Konstruksi.

Perubahan Peraturan Pemerintah Nomor 29 Tahun 2000.

Undang-Undang Republik Indonesia Nomor 2 Tahun 2017 Tentang Jasa Konstruksi.

Undang-Undang Republik Indonesia Nomor 18 Tahun 1999 Tentang Jasa Konstruksi. 